\title{
"A Case Report on T2dm With Systemic Amyloidosis Leading To Non Diabetic Renal Disease."
}

\author{
Dr. Bharat Veer Manchanda ${ }^{1}$,Dr. Arun Khatri ${ }^{2}$,Dr. Saloni Mehra ${ }^{3}$, \\ Dr.Girish Dubey ${ }^{4}$,Dr. Saminder Chaudhary ${ }^{5}$,Dr.Ajay Arya ${ }^{6}$ \\ ${ }^{1}$ Assi. Professor in Dept of Medicine, Subharti Medical College, Meerut \\ ${ }^{2,4,5,6}$ Post Graduate In Dept Of Medicin, Subharti Medical College, Meerut \\ ${ }^{3}$ Post Graduate in Dept of Surgery, Subharti Medical College, Meerut
}

\section{INTRODUCTION}

The name AMYLOID is attributed to the pathologist Virchow, who in 1854 thought such deposits in autopsy liver were cellulose because of their peculiar staining reaction with iodine and sulphuric acid.Amyloidosis is a term applied to a heterogeneous group of rare diseases characterized by extracellular deposition of amyloid (insoluble fibrillary proteins) causing target-organ dysfunction and a wide range of clinical symptoms. These symptoms depend on the organ involved, and include nephrotic syndrome, hepatosplenomegaly, congestive heart failure, carpal tunnel syndrome, gastrointestinal (GI) symptoms and macroglossia.

It is estimated that about $20 \%-40 \%$ of patients with type 1 or type 2 diabetes will develop diabetic nephropathy (DN), which contributes to most end-stage renal disease worldwide. Diagnosis of DN is mostly clinically based on a long history of diabetes, proteinuria, hypertension, and a progressive decline in renal function. This diagnostic approach is inconclusive, due to the fact that non-diabetic renal disease (NDRD) has been found in type 2 diabetes mellitus (T2DM) patients. The prevalence of NDRD in type 2 diabetic patients with renal involvement varies from $20-80 \%$. The diagnose of NDRD in diabetic patients has an obvious prognostic and therapeutic importance. The common NDRD includes glomerulonephritis, vascular nephropathy, cholesterol microembolism and so on. Systemic amyloidosis is a rare disease with an incidence of 4.5 per 100000 person-years. The pathological production of fibrillar proteins can deposit in numerous tissues and cause organ dysfunction including kidney, liver, heart, lung, spleen, gastrointestinal tract and bladder. Here, we describe a rare case of type 2 diabetes presenting with massive proteinuria due to primary systemic amyloidosis.

\section{Case report}

A 60-year-old female presented with chief complain of b/l pitting oedema of legs, generalized weakness and frothy urine for 3 weeks. She was diagnosed type 2 diabetes on routine testing 14 years and was on regular treatment (OHA). There was no history of diabetic retinopathy or neuropathy. she denied family history of diabetes or systemic disease.

On Examination :- Her general condition was unsatisfactory his initial blood pressure in left arm supine position was 130/90 and pulse rate of 88/min. Pallor was present, Icterus, cyanosis, Lymph node absent, b/l lower limb pitting oedema present. Her random blood sugar was $142 \mathrm{mg} / \mathrm{dl}$ by glucometer.

CNS:-WNL Patient was conscious oriented to time, place, person

CVS :- S1S2+, No added sound, no murmur was heard

$\mathrm{R} / \mathrm{S}:-\mathrm{B} / \mathrm{L} \mathrm{AE}+$, normal vesicular breath sound,

P/A:- Soft, Non-tender, liver palpable 1-2cm

Her initial investigation revealed microcytic, hyprochromic anemia (Hb 8.2 method photometry, Wbc 7.6 method electrical impedence), RFT (B.urea 42, method urease with Indicator dye, S.cret 1.2method enzymatic, Na134 method Direct ISE, K 4.40 method direct ISE) LFT (bil 1.2 method azobilirubin/dyphylline, sgot 52 sgpt 60 method kinetic with pyridoxal phosphate, alp 78 method method pnpp/amp buffer, total protein 4.2 method biuret(alkaline cupric sulphate), albumin 1.8 globulin 2.4 (calculated)

Urine routine/Microscopy revealed pulse as 2-3/HPF, RBC 4-5/HPF, Epithelial Cell 1-2/HPL, Albumin ++++, Sugar+, method Dipstic Reflectance Spectrophotometry/Microscopy. Viral markers were negative. 24 hour urine protein $4.8 \mathrm{gm}$. USG (W/A) was done which was suggestive of hepatomegaly and rt kidney enlarged in size with maintened cmd and echotexture.

Abdominal fat pad aspiration was done which came out to be positive for amyloid. 


\section{DISCUSSION}

Diabetic nephropathy is a complication of diabetes associated with the kidney which could progressively lead to end-stage renal diseases. The diagnosis of DN is frequently based on clinical characterization exclusively. Actually, a variety of NDRDs are often overlooked in diabetic patients, which have significant impacts on prognosis and treatment. The challenges still exist to differentiate NDRD from DN in diabetic patients.The definitive diagnosis of amyloid is usually based on the typical histopathological findings of amyloid in the affected tissue. . Therefore, renal biopsy is the only tool to diagnose NDRD. However, the renal biopsy cannot be used as a routine diagnostic test in type 2 diabetic patients with proteinuria because of the invasiveness. Therefore, the main indication for renal biopsy was clinically thorough suspicion of NDRD. The common indications for NDRD in type 2 diabetes are short duration of type 2 diabetes, acute or rapidly progressive renal failure, glomerular hematuria, absence of diabetic retinopathy, nephritic syndrome with normal renal function. As in our case, despite the patients having T2DM for more than 10 years, high level of proteinuria without retinopathy suggests a diagnosis of NDRD other than DN. Thus, biopsy was considered in our patient for the precise diagnosis(abdominal sub cutaneous fat pad aspiration ).

Abdominal subcutaneous fat pad aspiration is a non aggressive technique with good sensitivity, minimally invasive, outpatient based, quick, easy, reproducible and repeatable procedure and widely used as a screening test in diagnosis of systemic amyloidosis . A wide spectrum of NDRNs reported in patients with type 2diabetes mainly include glomerular and tubulointestinal lesions .our case, we diagnosed the systemic amyloidosis which is aninfrequent cause of non-diabetic renal disease in patient with type 2diabetes based on positive Congo red staining.

Systemic amyloidosis is a rare and severe disease which involves several organs including kidney, liver, heart, lung, spleen, gastrointestinal tract, bladder and endocrine system and leads to a high motality rate .Without treatment, the median survival is less than 6 months .For all newly diagnosed cases of amyloidosis, an assessment of the specific type of amyloid is critical in ensuring proper therapy.Renal disease as a frequent manifestation of the systemic amyloidosis usually cause proteinuric renal failure in the context of normal or low blood pressure.

\section{References}

[1]. Kikkawa R, Koya D, Haneda M (2003) Progression of diabetic nephropathy.Am J Kidney Dis 41: S19-21.

[2]. ESRD Incidence Study Group, Stewart JH, McCredie MR, Williams SM (2006)Geographic, ethnic, age-related and temporal variation in the incidence of endstagerenal disease in Europe, Canada and the Asia-Pacific region, 1998-2002.Nephrol Dial Transplant 21: 2178-2183.

[3]. Tone A, Shikata K, Matsuda M, Usui H, Okada S, et al. (2005) Clinical featuresof non-diabetic renal diseases in patients with type 2 diabetes. Diabetes ResClin Pract 69: 237-242.

[4]. Richards NT, Greaves I, Lee SJ, Howie AJ, Adu D, et al. (1992) Increasedprevalence of renal biopsy findings other than diabetic glomerulopathy in typeII diabetes mellitus. Nephrol Dial Transplant 7: 397-399.

[5]. Prakash J, Sen D, Usha, Kumar NS (2001) Non-diabetic renal disease inpatients with type 2 diabetes mellitus. J Assoc Physicians India 49: 415-420.

[6]. Schwartz MM, Lewis EJ, Leonard-Martin T, Lewis JB, Batlle D (1998) Renalpathology patterns in type II diabetes mellitus: relationship with retinopathy.The Collaborative Study Group. Nephrol Dial Transplant 13: 2547-2552.

[7]. Merlini G, Stone MJ (2006) Dangerous small B-cell clones. Blood 108: 2520-2530.

[8]. Zhou J, Chen X, Xie Y, Li J, Yamanaka N, et al. (2008) A differential diagnosticmodel of diabetic nephropathy and non-diabetic renal diseases. Nephrol DialTransplant 23: 1940-1945.

[9]. Christensen PK, Larsen S, Horn T, Olsen S, Parving HH (2000) Causes ofalbuminuria in patients with type 2 diabetes without diabetic retinopathy. KidneyInt 58: 1719-1731.

[10]. Kasinath BS, Mujais SK, Spargo BH, Katz AI (1983) Nondiabetic renal diseasein patients with diabetes mellitus. Am J Med 75: 613-617.

[11]. Zhuo L, Ren W, Li W, Zou G, Lu J (2013) Evaluation of renal biopsies in type 2diabetic patients with kidney disease: a clinicopathological study of 216 cases.Int Urol Nephrol 45: 173-179.

[12]. Pham TT, Sim JJ, Kujubu DA, Liu IL, Kumar VA (2007) Prevalence ofnondiabetic renal disease in diabetic patients. Am J Nephrol 27: $322-328$.

[13]. Ozdemir D, Dagdelen S, Erbas T (2010) Endocrine involvement in systemicamyloidosis. Endocr Pract 16: $1056-1063$.

[14]. Obici L, Perfetti V, Palladini G, Moratti R, Merlini G (2005) Clinical aspects ofsystemic amyloid diseases. Biochim Biophys Acta 1753: $11-22$.

[15]. Kyle RA, Gertz MA (1995) Primary systemic amyloidosis: clinical and laboratoryfeatures in 474 cases. Semin Hematol 32: $45-59$.

[16]. Gertz MA (2012) How to manage primary amyloidosis. Leukemia 26: 191-198.

[17]. Mohty D, Pibarot P, Dumesnil JG, Darodes N, Lavergne D, et al. (2011) Leftatrial size is an independent predictor of overall survival in patients with primarysystemic amyloidosis. Arch Cardiovasc Dis 104: 611-618. 